\title{
A construção da governança ambiental na RDS Igapó-Açu (Amazonas, Brasil): organização, complexidade e interdependência
}

\section{The construction of environmental governance in the RDS Igapó-Açu (Amazonas, Brazil): organization, complexity and interdependence}

\author{
Marília Gabriela Rezende \\ Therezinha de Jesus Pinto Fraxe ${ }^{b}$ \\ Antônio Carlos Witkoskic
}

${ }^{a}$ Doutoranda no Programa de Pós-Graduação em Ciências do Ambiente e Sustentabilidade na Amazônia, Universidade Federal do Amazonas, Manaus, AM, Brasil End. Eletrônico: m.aril.iagabriela@hotmail.com

${ }^{\mathrm{b}}$ Professora Associada da Universidade Federal do Amazonas, Manaus, AM, Brasil End. Eletrônico: tecafraxe@uol.com.br

'Professor Associado da Universidade Federal do Amazonas, Manaus, AM, Brasil End. Eletrônico: acwitkoski@yahoo.com.br

doi:10.18472/SustDeb.v7n2.2016.18100

Recebido em 07.03.2016

Aceito em 19.07.2016

ARTIGO - VARIA

\section{RESUMO}

O objetivo principal desta pesquisa foi analisar a governança ambiental na Reserva de Desenvolvimento Sustentável Igapó-Açu, localizada nos municípios de Manicoré, Borba e Beruri. A escolha da área de estudo deve-se ao fato de a RDS Igapó-Açu ser a única Unidade de Conservação (UC) do Amazonas atravessada por uma rodovia federal, o que lhe confere um ordenamento territorial específico e reconfigura os elementos constituintes da governança nesse território. Para atingir os objetivos foram utilizados diferentes instrumentos metodológicos como formulários e entrevistas abertas. Os dados foram sistematizados no Programa Excel e posteriormente representados em forma de organogramas, produzidos por meio do Programa Websphere Analysis. Os resultados da pesquisa indicam que a tessitura da governança ambiental da RDS Igapó-Açu envolve múltiplos fatores, entretanto, a centralidade da rede de articulação política é ocupada pelo Conselho Gestor, que conduz à materialização da governabilidade da UC e de seus desdobramentos.

Palavras-chave: Governo. Governabilidade. Redes. 


\begin{abstract}
The main objective of the present text is to analyze environmental governance in the Sustainable Development Reserve Igapó-Açu, located in the municipalities of Manicoré, Borba and Beruri, state of Amazonas, Brazil. The study area was chosen because the RDS is the only Amazonas state protected area crossed by a federal interstate highway. This highway provides a specific territorial arrangement of governance elements in the studied area. Different methodological tools were used in this research, such as close-ended questionnaires and open-ended interviews. Data were systematized using Excel software and they were graphically represented in the form of organizational charts drawn with Websphere Analysis Software. Results indicate that environmental governance of the RDS Igapó-Açu involves multiple factors, while the central node of the local political articulation is held by a Management Council that is in charge of materializing the governability of the RDSt, as well as its ramifications.
\end{abstract}

Keywords: Government. Governability. Networks.

\title{
INTRODUÇÃO
}

O sistema ambiental constitui-se pelo conjunto de condições que fornecem o fundamento para a reprodução da vida humana no planeta. Esse conjunto de condições é formado pela interação entre as camadas constituintes da Terra, sendo elas a hidrosfera, a litosfera, a atmosfera e a biosfera. A flexão na interação entre essas camadas gera problemas ambientais.

Esses problemas resultam da interferência na autopoiese ${ }^{1}$ do sistema ambiental, que modifica a organização da complexidade e seus desdobramentos sistêmicos. Por não se materializarem em um único território nacional e/ou local, os problemas ambientais transcendem as fronteiras dos Estados Nacionais, trazendo à tona a problemática da governança ambiental em suas múltiplas facetas.

A governança ambiental constitui-se por meio de sistemas simbólicos e sociopolíticos, que interagem incessantemente e materializam-se por meio da gestão territorial, modus operandi dessa governança. Dessa forma, uma análise profícua da governança ambiental deve abarcar, impreterivelmente, esses fatores complementares e cônjuges conformadores do sistema ambiental e de seus desdobramentos políticos.

Os sistemas simbólicos condicionam as relações sociais, exercendo, consequentemente, poder sobre os sistemas políticos. Isso ocorre devido ao fato de que as representações que os atores sociais têm do mundo derivam das objeções dos sistemas simbólicos (BOURDIEU, 2005) e dos constructos paradigmáticos no qual estão imersos. Torna-se, assim, imprescindível analisar a construção da governança ambiental na atualidade, visto os desdobramentos dessa governança nas relações sociais que se estabelecem cotidianamente nos mais variados territórios.

Dessa forma, com o agravamento significativo dos problemas ambientais nos últimos anos (20002014), o estado do Amazonas rediscutiu a problemática da governança ambiental e começou a buscar estratagemas que atenuassem o efeito maléfico do atual sistema econômico, criando as Unidades de Conservação, que são unidades territoriais criadas objetivando a preservação e a conservação de importantes ecossistemas. A política de criação de UC reconfigurou a governança ambiental no Amazonas, inserindo novos elementos na miríade analítica das estratégias de gestão e mitigação dos problemas ambientais.

Entre as UC existentes no Amazonas, a RDS Igapó-Açu destaca-se por ser atravessada pela BR-319, essa distinção gera um ordenamento territorial específico e, por conseguinte, uma governança ambiental diferenciada, pelos distintos atores sociais envolvidos na rede sociopolítica. Portanto, este artigo apresenta a organização da governança ambiental da RDS Igapó-Açu a partir da tessitura da rede de articulação política. 


\section{REVISÃO DA LITERATURA}

Atualmente, a significativa maioria dos trabalhos relacionados à governança ambiental está sendo publicada em outros países. No Brasil, as pesquisas nessa temática têm emergido com veemência nos últimos anos, devido à excrescência de olhares sobre a biodiversidade amazônica. As pesquisas de destaque internacional sobre governança centram-se nos trabalhos de Biermann (2004), Najam, Papa, Taiyab (2013), Esty e Ivanova (2003).

Esses autores estudam a governança ambiental global na perspectiva política e econômica, entretanto, deixam lacunas no entendimento sistêmico e transdisciplinar da rede de articulação política, pois não mencionam a influência que as formas de organização social exercem na configuração da governança. Alguns trabalhos importantes na temática da governança têm emergido no cenário internacional e superado algumas dessas lacunas, com destaque para os trabalhos de Lemos e Agrawal (2006) e Delmas e Young (2009), porém, no Brasil essa discussão sobre governança na perspectiva sistêmica tem sido pouco explorada.

No Brasil, as pesquisas com significativo impacto estão centradas nos trabalhos de Veiga (2009), Ribeiro (2005) e Haesbaert (1994 e 2005). Esses autores trabalham a governança a partir da compreensão da interação entre as escalas global-local, entretanto, a ênfase na temática aplicada à UC ainda não é acentuadamente explorada, exceto pelas organizações governamentais e não governamentais.

A governança, aqui tratada, transcende escalas, devido à interação sistêmica entre os seus componentes. O ordenamento territorial, expressão material da governança, é resultante das metamorfoses do espaço habitado ${ }^{2}$ (SANTOS, 1994), a organização da vida no território é completamente dependente da imbricação entre o externo e o interno, de modo que as variáveis externas se internalizam e as variáveis internas se externalizam, dialeticamente.

O ordenamento territorial, materialização da governança e da articulação entre as organizações sociais, constitui e é constituído por uma rede de articulação política, que extrapola as fronteiras escalares e explicita as interações incessantes do social no contemporâneo. Mas, se a governança é uma rede de articulação política, torna-se imprescindível compreender a natureza e as imbricações dessa rede no âmbito das diferentes expressões da sociedade.

Segundo Castells (2002), as redes são morfologias sociais e políticas da sociedade contemporânea, e representam-se por um conjunto de nós interconectados, expressos por meio do poder dos fluxos e dos fluxos de poder. A concretude da rede não é estática, e pode ser modificada à medida que se reconstroem os nós de interconexão. Exemplifica-se essa constante ressignificação dos nós, da referida rede, a partir do Conselho Gestor, que congrega diferentes atores sociais.

Existem outros autores que trabalham a noção de redes, como Dias (1995) e Latour (2005), entretanto, optou-se pelo aprofundamento dessa categoria em Castells (2002). Nesse sentido, a rede é entendida como uma representação da conectividade e da dinâmica da complexidade entre os atores sociais que se articulam no emaranhado de nós correlacionados. Dessa forma, as redes apresentam-se como híbridos móveis, como cadeias associativas das relações onde há correlação de forças políticas. Assim, o corpo social reflete e é refletido por essas redes, de modo que constroem e reconstroem os seus nós constituintes.

Para compreender a organização e constituição da governança é necessário explicitar os sistemas simbólicos e a conformação paradigmática que origina os sistemas sociopolíticos. Para Bourdieu (2005), o sistema simbólico é o modo como se organiza o poder invisível que reproduz a ordem social. Para Elias (1994), esse sistema orienta o comportamento dos seres humanos por meio do habitus em relação ao conhecimento apreendido, esses dois elementos permitem a constituição dos símbolos, que não se traduzem apenas na abstração.

Dessa forma, os símbolos se organizam sistemicamente, formando os sistemas simbólicos, que fornecem o fundamento subjetivo e material necessário para a formação dos sistemas sociopolíticos. Os sistemas políticos, por sua vez, são o reflexo material dos sistemas simbólicos, expresso na transver- 
salidade espaço-temporal entre o significado ${ }^{3}$ e o significante ${ }^{4}$. A interação entre esses dois sistemas gera o ordenamento territorial, que é a expressão espacial do processo de relação e interação social.

Nesse sentido, o conceito de governança ambiental utilizado neste artigo foi construído a partir das lacunas identificadas em pesquisas anteriores, que não inserem na análise da governança as formas de organização social. Assim sendo, neste trabalho a governança ambiental é conceituada como uma rede de articulação política oriunda das diferentes formas de organização social, que imbricam sistemas simbólicos e sociopolíticos.

\section{MÉTODOS}

\section{ÁREA DE ESTUDO}

Esta pesquisa foi realizada na Reserva de Desenvolvimento Sustentável (RDS) Igapó-Açu, localizada no estado do Amazonas, mais precisamente nos municípios de Beruri, Borba e Manicoré (Figura 1), entre os rios Purus e Matupiri. Possui uma área de aproximadamente 397.557,323 ha, cujos limites territoriais fazem fronteira com a Terra Indígena (TI) Cunhã-Sapucaia, com o Projeto de Assentamento Agroextrativista Tupana Igapó Açu I e II, com o Parque Estadual (Parest) do Matupiri, com a RDS Rio Amapá e com o Parque Nacional de Nascentes do Lago Jari. A intersecção de áreas fronteiriças com UC e TI confere um caráter singular à RDS Igapó-Açu.

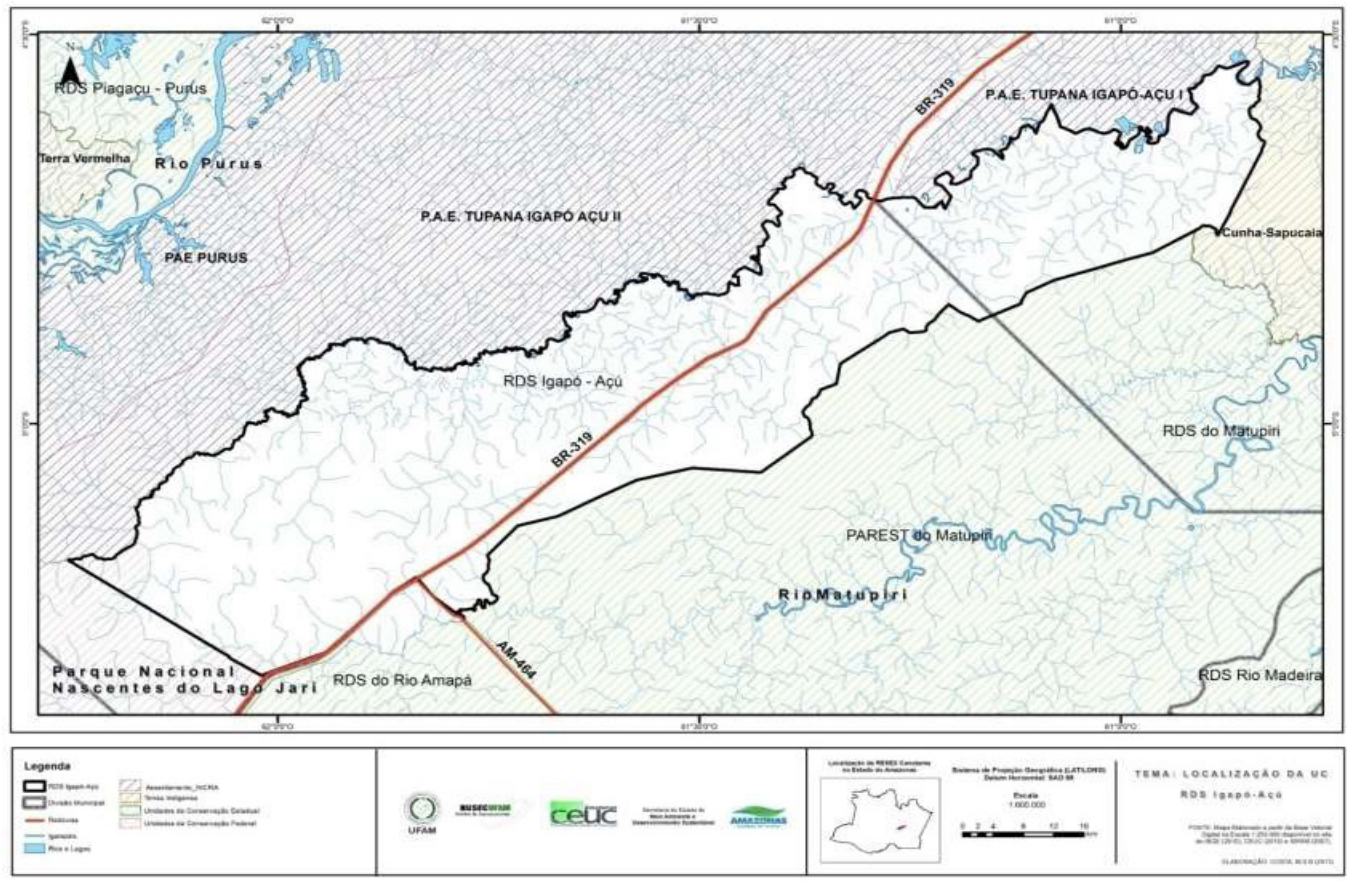

Figura 1 - Localização da RDS Igapó-Açu.

Fonte: NUSEC, 2015. Org.: REZENDE e COSTA, 2015.

A RDS Igapó-Açu foi instituída em 2009, por meio do Decreto Estadual n. 28.420, e tem como órgão gestor o Departamento de Mudanças Climáticas e Unidades de Conservação (Demuc). As principais atividades econômicas desenvolvidas na UC são a pesca e a agricultura, entretanto, alguns moradores trabalham com atividades voltadas ao turismo de pesca esportiva. A UC contempla em sua infraestrutura a presença de uma escola, porém, é ausente de postos de saúde e de outros elementos básicos de infraestrutura.

A RDS Igapó-Açu é uma das UC do estado do Amazonas que apresentam peculiaridades no que concerne ao ordenamento territorial, pois é atravessada por uma rodovia federal, a BR-319. Nesse sentido, 
torna-se imprescindível analisar como é constituída a governança ambiental nessa RDS no âmbito dessas singularidades territoriais. Porém, para entender a construção da governança ambiental nessa área é necessário compreender o ordenamento territorial e a conformação paisagística existente, pois esses elementos prescindem a análise da rede de articulação política que constitui a governança ambiental.

O rio se apresenta como o principal veículo no que se refere à mobilidade das atividades produtivas e possui significado simbólico, construído e perpassado geracionalmente. Dessa forma, o Rio Igapó-Açu passa a ser um símbolo, na medida em que há a atuação relacional entre os significantes e os significados. Os significantes são os membros da família que transmitem geracionalmente os significados que Ihe são adequados. O significado desse símbolo está além do sentido objetivo de realização da pesca, de mobilidade da agricultura e de desenvolvimento do lazer, tendo também sentido subjetivo, na medida em que representa simbolicamente um lugar, em essência topofílico ${ }^{5}$.

Entretanto, esse símbolo atua representando contraditoriamente na área de estudo uma segregação social, na medida em que o rio delineia os conflitos existentes entre duas comunidades localizadas nas suas margens, compostas do lado esquerdo pela Comunidade São Sebastião do Igapó-Açu e do lado direito pela Comunidade Nova Geração. Esse conflito, caracterizado pela disputa por recursos naturais (peixe e caça), é geracional e ocasiona reflexos significativos na gestão territorial e ambiental, com consequências na rede política que constitui a governança e o governo na UC.

Antes de elucidarmos o engendramento entre esses atores sociais é necessário entender como se constitui a RDS Igapó-Açu enquanto unidade territorial. Uma unidade territorial não significa a divisão unitária de um espaço, mas a delimitação territorial seguida de critérios específicos. Assim sendo, a RDS Igapó-Açu é uma unidade territorial que contempla diferentes geossistemas que se entrecruzam formando um território peculiar, composto de diferentes territorialidades.

\section{COLETA E ANÁLISE DE DADOS}

Inicialmente, a pesquisa foi cadastrada na Plataforma Brasil para análise do Comitê de Ética, sendo aprovada sob o número 49472115.6.0000.5020. Após autorização legal, foram realizados 05 trabalhos de campo, sendo 04 deles desenvolvidos na estação chuvosa e 03 deles na estação seca. No primeiro trabalho de campo executou-se o estudo exploratório, onde foi identificado o problema da pesquisa. No segundo, foram realizadas entrevistas abertas para elucidar as possíveis perguntas para a constituição dos formulários. No terceiro, foi executado o pré-teste e realizado algumas entrevistas abertas com as lideranças comunitárias.

No quarto e quinto trabalho de campo, foram aplicados formulários com as famílias da RDS Igapó-Açu. Por fim, foi realizado o quinto trabalho de campo, para a validação dos dados e preenchimento de algumas lacunas da pesquisa. A vivência na área de estudo permitiu o conhecimento mais próximo do real, por meio da interação com os atores sociais da pesquisa. Portanto, esses foram os caminhos utilizados para a construção da pesquisa e do artesanato intelectual.

Os procedimentos metodológicos utilizados para a realização da pesquisa centraram-se no levantamento de dados primários e secundários, em aplicação de formulários e em entrevistas abertas. Esses instrumentos deram o suporte necessário para a geração de dados que foram sistematizados e representados em forma de organogramas e trabalhados via Programa Websphere Analysis. O critério estatístico definido para o detalhamento do desenho amostral foi a abordagem estatística não probabilística. No total foram aplicados formulários com $100 \%$ das famílias da RDS Igapó-Açu, abarcando tanto a Comunidade São Sebastião do Igapó-Açu quanto a Comunidade Nova Esperança.

As entrevistas abertas foram realizadas com as lideranças da comunidade, e os formulários com os chefes de domicílio de todas as famílias que compõem a RDS Igapó-Açu. As principais perguntas existentes no formulário que conduziram a pesquisa indagavam qual era a participação de cada família nas reuniões do Conselho Gestor, quais as instituições atuantes na UC, se havia participação em alguma forma de organização social, entre outras. Os dados adquiridos foram transferidos para uma planilha em Excel e, posteriormente, organizados no Programa Websphere Analysis, software utilizado para a representação de dados em forma de organogramas. 
Após a coleta e análise dos dados obtidos por meio de formulários, foi realizada uma oficina participativa com $70 \%$ das famílias da RDS Igapó-Açu, para a validação dos dados coletados e dos resultados da pesquisa. As entrevistas abertas tiveram duração de aproximadamente 20 minutos, foram realizadas com os líderes comunitários, e tinham como objetivo compreender os aspectos históricos da criação da RDS bem como os conflitos existentes, imprescindíveis para a análise da governança nessa unidade territorial.

\section{RESULTADOS E DISCUSSÕES}

Os resultados da pesquisa, oriundos da discussão acerca do objetivo principal, tiveram como fio condutor a organização da governança ambiental da RDS Igapó-Açu construída a partir dos dados coletados. Nesse sentido, os resultados foram organizados a partir de três elementos importantes, sendo, respectivamente, a participação em organizações sociais, a organização do Conselho Gestor e o policentrismo. A participação em organizações sociais (Figura 2) é uma característica marcante da RDS Igapó-Açu, pois $67 \%$ das famílias participam de alguma forma de organização social.

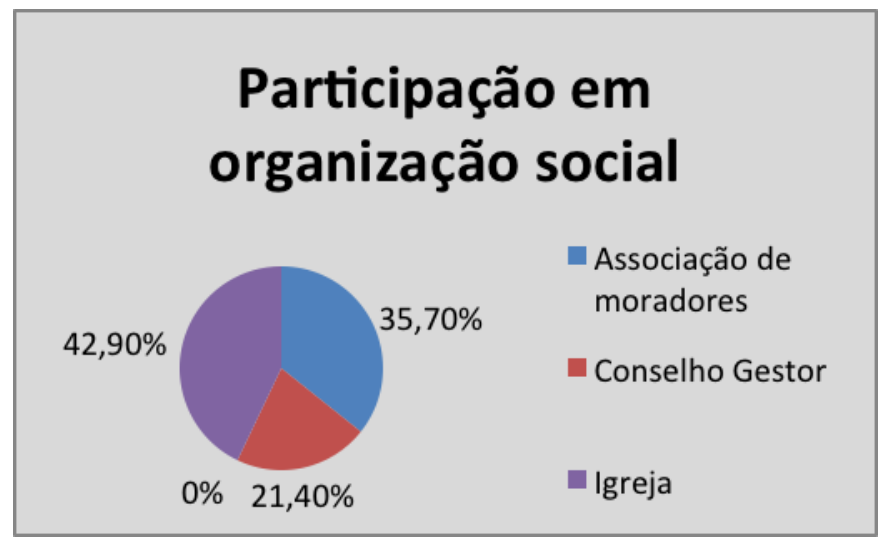

Figura 2 - Tessitura da rede de articulação política.

Fonte: REZENDE, 2015.

Do total de famílias partícipes em organizações sociais, 42,90\% frequentam igreja, 35,70\% participam da Associação de Moradores e 21,40\% participam do Conselho Gestor. A significativa participação das famílias na igreja justifica-se por inúmeros fatores, com destaque para a reterritorialização do sagrado instituído socialmente nos locais de nascimento e socialização, e para realização das festas religiosas. A participação dos moradores da RDS na Associação de Moradores não ocorre de modo efetivo, visto que, nos últimos anos, há ausência de $90 \%$ dos associados nas reuniões da associação. O Conselho Gestor é a organização social de maior influência na RDS, pois condensa e conforma a rede de articulação política que configura a governança ambiental na área de estudo.

O Conselho da RDS Igapó-Açu é de caráter consultivo, e os processos de tomada de decisão concentram-se na chefia da UC, representada pelo Departamento de Mudanças Climáticas e Unidades de Conservação (Demuc). Os representantes dos moradores da UC, antes das reuniões do Conselho Gestor, listam junto à comunidade as demandas sociais, para apresentação em reunião. Dessa forma, as deliberações e os processos de tomada de decisão ocorrem de forma participativa.

A área correspondente a essa RDS contempla atores sociais de múltiplas naturezas: moradores da RDS, organizações governamentais e sociopolíticas, e representantes do ramo empresarial (Figura 3). Esses quatro grandes grupos compõem o Conselho Gestor da RDS Igapó-Açu que, segundo o Sistema Nacional de Unidades de Conservação (2000), é um espaço público jurídico-institucional que objetiva o planejamento participativo na elaboração e execução das políticas públicas. Dessa forma, é o principal espaço político de manifestação da governança. 


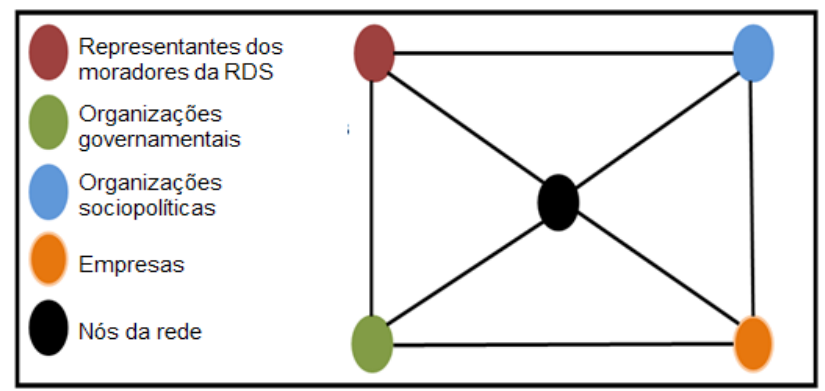

Figura 3 - Tessitura da rede de articulação política.

Fonte: REZENDE, 2015.

O Conselho Gestor, constituído pelos quatro grupos elencados na figura acima, representa um nó na rede de articulação política que configura a governança na RDS Igapó-Açu, devido à força centrípeta que exerce na organização dos atores sociais influentes na rede política da UC. Dessa forma, observase que há quatro grupos de atores sociais envolvidos que compõem a tessitura da governança na RDS Igapó-Açu.

Os representantes dos moradores da RDS Igapó-Açu possuem quatro membros no Conselho Gestor, cada membro representando um setor da RDS. Os representantes dos setores 01 e 02 simbolizam a margem direita do Rio Igapó-Açu, e os representantes dos setores 03 e 04 simbolizam a margem esquerda (Figura 4).

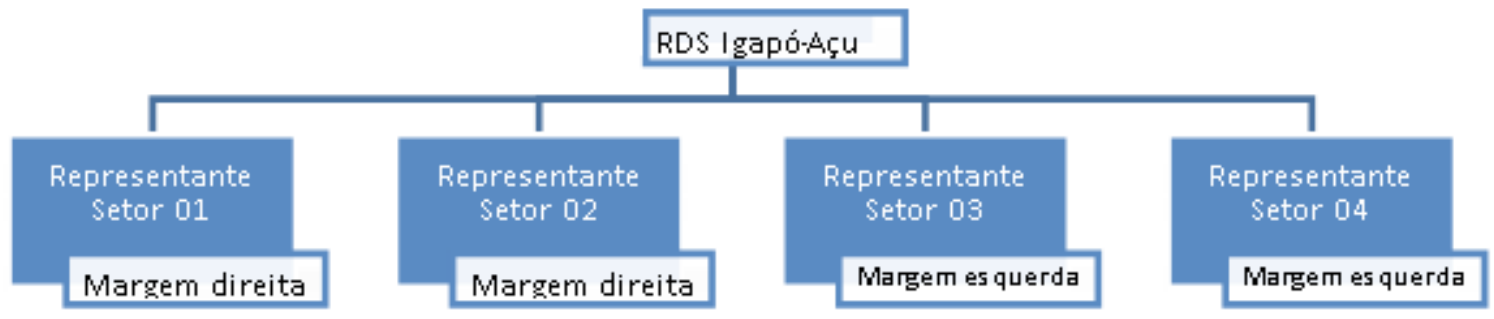

Figura 4 - Representantes da RDS Igapó-Açu no Conselho Gestor.

Fonte: REZENDE, 2015.

Os representantes da RDS Igapó-Açu contemplam a população residente na UC e na área de entorno. Outro grupo constituinte do Conselho Gestor são as organizações sociopolíticas, que representam a conjunção de interesses de um grupo social organizado. Diegues (2008), dissertando sobre o aumento da rede de poder das organizações sociopolíticas nas políticas ambientais estaduais e nacionais, colocou essas organizações como ponto central no entendimento da governança ambiental global.

Na RDS Igapó-Açu, a atuação dessas organizações tem se manifestado paulatinamente (Figura 5), com uma organização interna peculiar, reconfigurando a centralidade das redes políticas existentes. Cada organização sociopolítica defende seus interesses e insere novos elementos na miríade de gestão territorial, tendo influência marcante no gerenciamento da UC. 


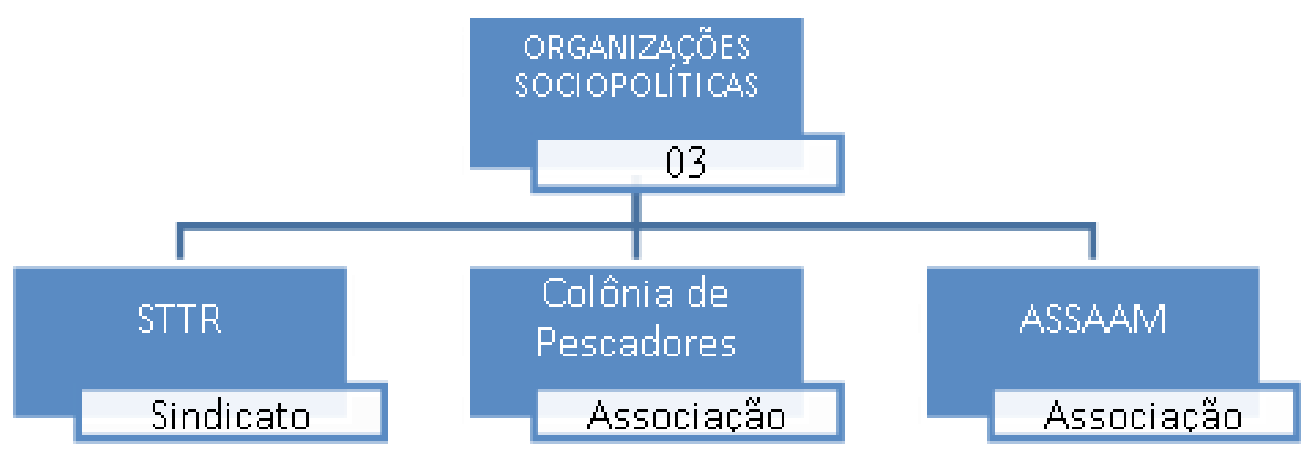

Figura 5 - Espacialização das organizações sociopolíticas na RDS Igapó-Açu.

Fonte: REZENDE, 2015.

Identificou-se a atuação de 03 organizações sociopolíticas na área de estudo: o Sindicato dos Trabalhadores e Trabalhadoras Rurais do Careiro Castanho (STTR), a Colônia de Pescadores Z-49 e a Associação Amigos da Floresta (ASSAAM). Segundo Pinto (2002), o sindicato é uma organização composta por pessoas físicas e jurídicas, criada com o intuito de firmar interesses comuns à coletividade. No Amazonas, a criação de sindicatos é incipiente, se comparado aos outros estados brasileiros, entretanto, a legislação tem facilitado a criação e o desenvolvimento dos sindicatos, voltados às diversas temáticas (GOMES, 2011).

Paralelo a esse crescimento está a criação de associações, que são organizações formadas por duas ou mais pessoas, com gestão própria e sem fins lucrativos. A diferença entre um sindicato e uma associação está na natureza constitutiva, de modo que o sindicato representa politicamente uma determinada categoria, e a associação não se vincula necessariamente a uma categoria, mas aos objetivos comuns de uma coletividade.

O STTR do Careiro Castanho é um sindicato que atua na RDS Igapó-Açu na defesa dos trabalhadores e trabalhadoras rurais. Essa organização luta por melhorias relacionadas à infraestrutura para produção e escoamento dos produtos, além de incentivar as práticas agroecológicas na fruticultura, horticultura, entre outros. Sendo membro do Conselho Gestor da UC, o STTR tem poder de decisão nas discussões relacionadas ao planejamento e execução das atividades.

A Colônia dos Pescadores Z-49 é outra organização sociopolítica que compõe o Conselho da RDS Igapó -Açu. Possuem soberania quanto ao desenvolvimento de suas assembleias e executa, junto aos órgãos públicos, ações contra a degradação ambiental e a pesca predatória, sendo um importante instrumento que atua em paralelo com a gestão ambiental da UC.

As Colônias em UC têm se destacado pela desburocratização das normativas que regem o seguro defeso, além disso, têm fornecido acesso aos inúmeros benefícios advindos dos direitos dos pescadores e da pesca no Amazonas (LOPES et al., 2013). Dessa forma, pode-se compreender a relevância do exercício político da Colônia de Pescadores na RDS Igapó-Açu, pelo caráter dos benefícios sociais e econômicos que fornecem intrinsecamente aos pescadores, contribuindo para o desenvolvimento local dos moradores da UC.

Além do STTR e da Colônia de Pescadores Z-49, a Associação Amigos da Floresta (ASSAAM) compõe a tríade das organizações sociopolíticas que atuam na RDS Igapó-Açu. A ASSAAM é uma organização sem fins lucrativos, criada na UC para apoiar as atividades da Comunidade São Sebastião do Igapó-Açu e adjacências. Atualmente, essa associação apoia o desenvolvimento do turismo na RDS, e tem função importante no planejamento das principais festas temáticas, com destaque para a Festa do Tucunaré e para o Summer Fest Igapó-Açu.

Cada organização sociopolítica exerce suas funções dentro da unidade de forma diferenciada, pela natureza específica pela qual foram criadas. Entretanto, todas são importantes no desenvolvimento local dos moradores da RDS, não há graus de importância, mas exercícios de poder distintos, imprescindíveis no ordenamento territorial e nas formas de organização social. 
O terceiro grupo político, partícipe do Conselho Gestor, que compõe a rede de articulação política da RDS Igapó-Açu são as empresas. A inserção das empresas no Conselho Gestor da UC visa evitar possíveis conflitos que poderiam surgir com a efetivação das atividades empresariais e seus efeitos na conservação ambiental. Na área de estudo, 06 empresas possuem representantes no Conselho e têm influência nas discussões referentes à gestão territorial (Figura 6).

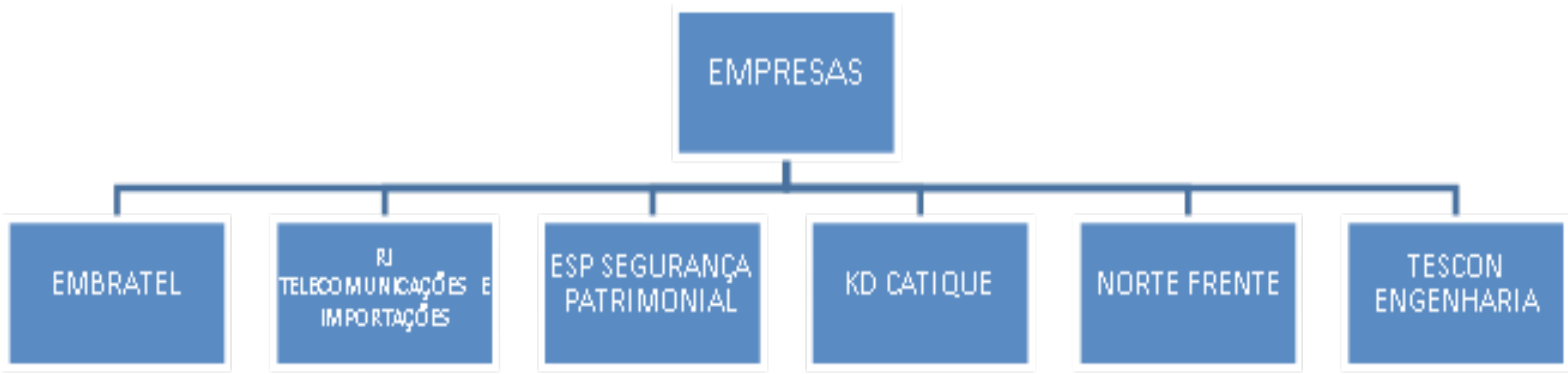

Figura 6 - Organograma das empresas membros do Conselho Gestor da RDS Igapó-Açu.

Fonte: REZENDE, 2015.

As empresas elencadas acima compõem o terceiro grupo de atores sociais envolvidos e partícipes do Conselho Gestor. Essas unidades econômicas devem planejar suas atividades de acordo com as normas estipuladas no Plano de Gestão, e devem contribuir para o aprimoramento das possíveis lacunas existentes no Plano de Manejo. Entretanto, a participação dessas empresas é de caráter consultivo, assim, por meio da participação social, os conselhos têm minimizado consideravelmente os conflitos existentes de ordem empresarial e comunitária.

O quarto grupo constitutivo do Conselho Gestor refere-se às organizações governamentais, composto por representantes de 07 órgãos estatais (Figura 7), sendo eles o Departamento de Mudanças Climáticas e Unidades de Conservação (Demuc), o Instituto Chico Mendes de Conservação da Biodiversidade (ICMBio), a Fundação Nacional de Saúde (Funasa), a Universidade Federal do Amazonas (Ufam), as prefeituras dos municípios de Careiro Castanho e Borba, e o Instituto de Desenvolvimento Agropecuário e Florestal Sustentável do Amazonas (Idam).

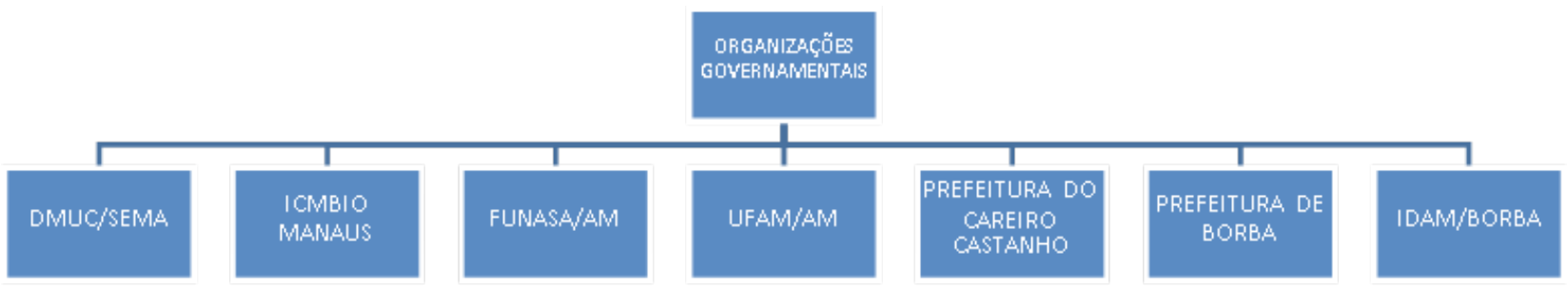

Figura 7 - Organizações governamentais membros do Conselho Gestor da RDS Igapó-Açu.

Fonte: REZENDE, 2015.

O Demuc, órgão vigente responsável pela gestão das áreas protegidas, representa atualmente a centralização da rede de articulação política, pois congrega as outras organizações governamentais no processo de planejamento e execução das atividades da RDS Igapó-Açu.

Os atores sociais descritos nos quatro grupos que compõem a rede política da RDS Igapó-Açu, no que concerne à constituição do Conselho Gestor, têm funções e objetivos específicos, de acordo com sua natureza jurídica. A rede política se materializa por meio da interação entre todos esses atores sociais envolvidos. A Figura 8 apresenta a tessitura da rede de articulação política da governança da RDS Igapó-Açu.

Pode-se afirmar que os quatro grupos, interagindo politicamente, configuram a rede de articulação política da governança ambiental da RDS Igapó-Açu, entretanto, a governança está para além dessas 
redes, apresentando e corroborando outros elementos, como a governabilidade e o governo. A governança ambiental é constituída a partir do entendimento dessa tríade (rede política, governabilidade e governo) formada pela interação entre os sistemas simbólicos e os sistemas sociopolíticos. O tópico seguinte aprofunda a inerência dessas questões e os seus desdobramentos na governança ambiental.

\section{A CENTRALIDADE DA REDE POLÍTICA E OS SISTEMAS POLICÊNTRICOS}

A governança ambiental é constituída por sistemas simbólicos e sistemas sociopolíticos que se configuram por meio da rede de articulação política existente. Para entender e analisar esse constructo que compõe a governança é necessário elucidar a tríade que a constitui para o aprofundamento das lacunas teóricas atuais. Essa não é uma tarefa fácil, pois desmistifica os axiomas e os paradigmas dominantes, que regeram desde sempre o pensar relacionado à governança na ciência moderna.

A significativa maioria dos trabalhos científicos que analisam a constituição da governança ambiental a concebem como sendo uma rede de articulação política entre os atores sociais que interagem em uma determinada área. Entretanto, essa é uma assertiva obscura, que exclui da construção teórica outros elementos imprescindíveis que resultam na organização de uma sociedade e, consequentemente, de um território.

A governança é construída e constrói-se por elementos da governabilidade e do governo (Figura 8). Porém, sua organização é precedida por sistemas simbólicos e sociopolíticos, que fundamentam e são fundamentados pelo governo, dialeticamente. O governo, a priori, não se reduz à dimensão do Estado, sendo a manifestação do poder pela unidade política gerida. Dentro dessa perspectiva, há uma interação política entre os atores sociais resultante de macroprocessos que se materializam via governança ambiental.

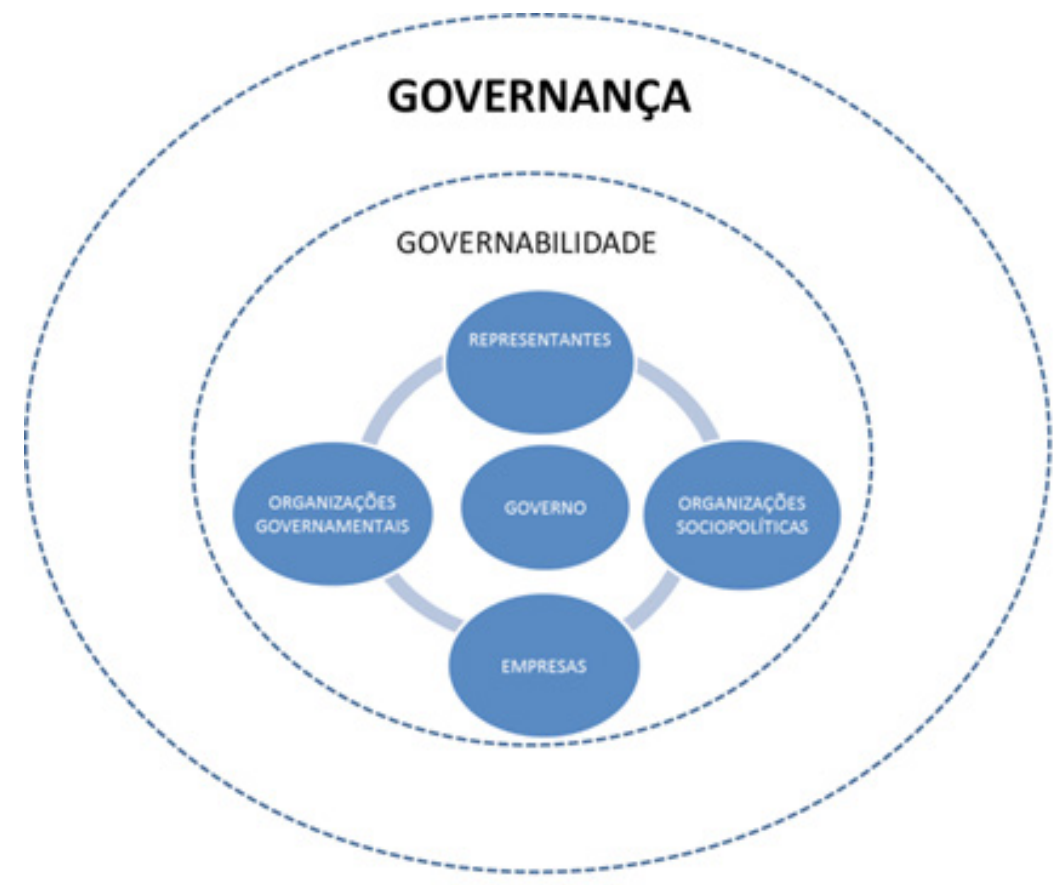

Figura 8 - Organização da governança ambiental na RDS Igapó-Açu.

Fonte: REZENDE, 2015.

As ações dos atores sociais da RDS Igapó-Açu, que compõem o Conselho Gestor, geram a governabilidade da UC. A governabilidade, aqui descrita, refere-se a todos os elementos que garantem as condições necessárias para o governo, no caso da área de estudo, é composta pelos grupos constituintes do Conselho: os representantes da RDS Igapó-Açu, as organizações governamentais, sociopolíticas, e as empresas. O papel desses atores sociais fundamenta a governabilidade da RDS Igapó-Açu. 
O governo da RDS Igapó-Açu é centralizado nos moradores, apesar da influência marcante do Demuc na execução das atividades cotidianas. Entretanto, isso não significa que o governo independe dos outros grupos que compõem a rede política da UC, pelo contrário, os outros atores sociais fundamentam a governabilidade para o exercício desse governo. Por esse motivo, é impossível analisá-lo sem compreender as interações que o constituem enquanto organizador da unidade política.

Apesar de a RDS Igapó-Açu ser constituída por pessoas advindas dos diversos lugares do Brasil, possui características específicas resultantes da materialização dos sistemas simbólicos após a socialização com o grupo anteriormente territorializado. Nesse contexto, o poder que orienta o ordenamento do território e que governa a UC está centralizado nos moradores antigos, que estabelecem normas de uso territorial para os novos moradores.

Essas normas são baseadas na sustentabilidade cultural, apreendida geracionalmente por meio da materialização dos sistemas simbólicos, constituintes da cultura ${ }^{6}$, via oralidade. Na RDS Igapó-Açu há inúmeras características marcantes de gestão dos bens comuns que se assemelham às práticas tradicionais de uso da terra. Pode-se inferir que essa UC está em um processo de reinvenção do tradicional, ou seja, em uma nova configuração cultural de gestão ambiental dos bens comuns, pautado, sobretudo, na sustentabilidade ambiental.

Segundo Duarte (2014), a sustentabilidade adquiriu um caráter polissêmico na atualidade, na medida em que vem se reconfigurando ao longo do tempo. A emergência desse conceito deve-se à extrema dependência da sociedade com o ambiente, anteriormente negligenciada pela modernidade. Assim, a sustentabilidade foi inserida no campo da discussão paradigmática, por se tratar de uma nova construção social em emergência. Nascimento (2012) afirma que a sustentabilidade está ancorada em modos particulares de relação com o ambiente, e tem como objetivo principal a manutenção da resiliência ecossistêmica a partir da solidariedade por meio de princípios éticos específicos.

Pode-se observar que, apesar da polissemia do termo sustentabilidade, os autores que escrevem sobre essa temática encontram pontos semelhantes, independente do nó górdio existente entre as diversas abordagens. Neste artigo, a sustentabilidade ambiental será empregada como sendo o processo de utilização dos bens comuns sem destituir a autopoiese do sistema ambiental.

Os moradores antigos da RDS Igapó-Açu possuem um saber perpassado geracionalmente que assegura a sustentabilidade ambiental. Eles desenvolvem atividades na agricultura e na pesca que proporcionam e corroboram a autopoiese sistêmica. Utilizam produtos naturais no controle das pragas, em detrimento do uso de agrotóxicos; plantam em rotatividade, para não esgotar os nutrientes do solo; pescam em momentos propícios e respeitam o período de defeso, para evitar a extinção das espécies, entre outros.

As formas específicas e coletivas de gestão dos bens comuns ambientais, em foco, resultam no governo da RDS Igapó-Açu. Esse governo representa a materialização dos sistemas simbólicos no ordenamento da unidade política. A governação, ou seja, o resultado da ação de governar advém dos pressupostos culturais e paradigmáticos de uma sociedade, e na área de estudo não é diferente. É importante ratificar que o governo é conduzido por seres humanos e, portanto, por seres que possuem paradigmas que comandam e gerem os seus modos de pensar, formular e executar políticas. Logo, isento de neutralidade.

Compreender a governança destituída da natureza do governo e da governabilidade significa construir uma análise simplista, por esse motivo, foi necessário esclarecer e extinguir a membrana de opacidade que vem orientando o pensar político na ciência moderna. Nesse sentido, a governança, aqui trabalhada, será a rede de articulação política entre os atores sociais e os sistemas simbólicos e sociopolíticos que originam o governo e concebem a governabilidade.

A partir dessa contextualização, nota-se que o Conselho Gestor passa a ser um dos principais instrumentos da governança ambiental da RDS Igapó-Açu, pois, por meio de reuniões, materializa a rede política que compõe a governabilidade da unidade. Pode-se afirmar, veementemente, que o Conselho representa a centralidade da governança, por garantir a governabilidade e ter significativa influência no governo. 
Lefebvre $(2008$; 1999) entende centralidade como a capacidade de polarização, controle e atração dos fluxos de uma rede. Entretanto, essa centralidade deve ser entendida pela lógica da dialética no processo de construção e reconstrução das polarizações. O centro emerge nessa discussão como uma realidade material, e a centralidade como uma realidade imaterial, porém, que proporciona a materialização da polaridade da rede.

A importância do Conselho tem sido discutida amplamente, em nível estadual e nacional, pelo seu papel na governabilidade das áreas protegidas e pela imprescindibilidade que exercem no âmbito da governança ambiental. A integração dos atores sociais que agem na UC está potencializando-se com as reuniões entre os conselheiros, que ocorrem bimestralmente.

Apesar da centralidade da rede da governança ambiental ser o Conselho Gestor, a RDS Igapó-Açu é uma unidade territorial policêntrica, pois os centros de poder se espacializam em diferentes locais. A centralidade da rede, no caso desta UC, é constituída por vários centros localizados internamente. Nesse sentido, os centros da Comunidade São Sebastião do Igapó-Açu se concentram no Chapéu de Palha e na sede da ASSAAM (Figura 9), na Pousada da Dona Mocinha, lugar de frequente encontro dos moradores e de sociabilidade ${ }^{7}$. Os Chapéus de Palha são arquiteturas encontradas em grande parte da Amazônia, construídos para abarcar encontros entre os membros de uma ou mais comunidades.

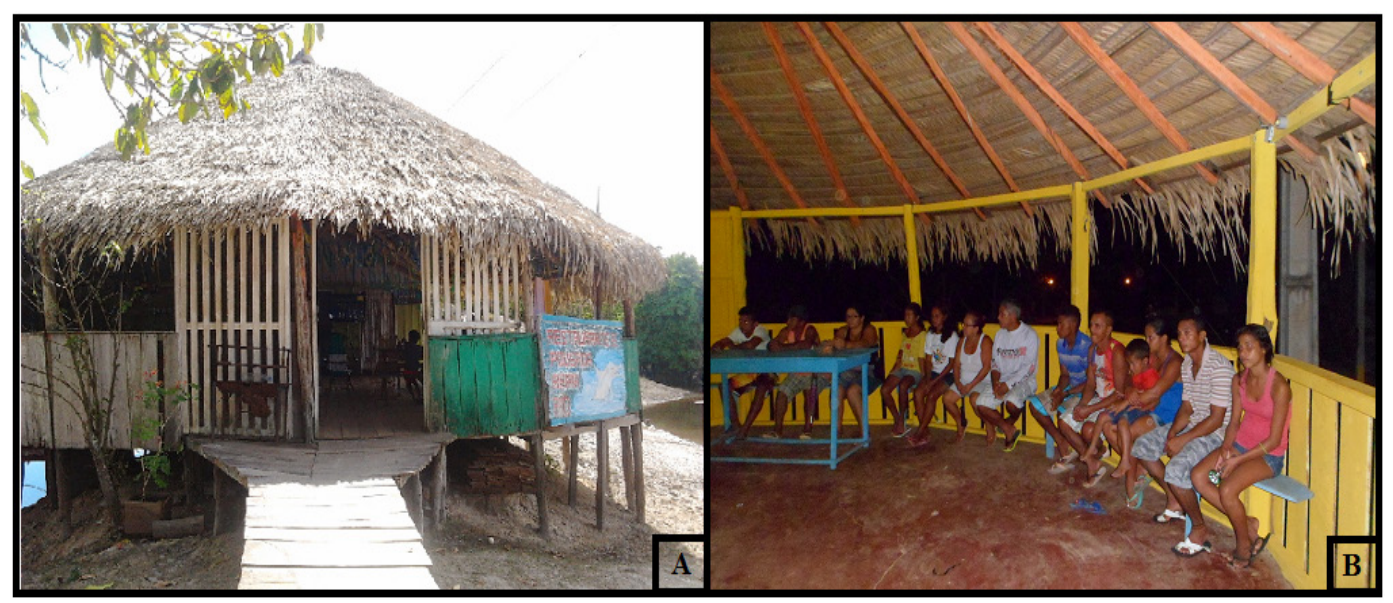

Figura 9 - Centros da Comunidade Igapó-Açu.

Esquerda: Pousada da Dona Mocinha; Direita: Chapéu de Palha. Fonte: REZENDE, 2015.

A Pousada da Dona Mocinha recebe os moradores da comunidade supracitada, turistas e moradores de outras comunidades. Destaca-se, nos finais de tarde e no período noturno, por conglomerar os comunitários na área externa para a realização de bingos e de outras atividades. Os bingos, na área de estudo, são pontos importantes de integração social entre as comunidades conflitantes, sendo um instrumento de lazer com significativa função social.

Pode-se compreender que as atividades desenvolvidas nos centros da Comunidade São Sebastião do Igapó-Açu são imprescindíveis para o desenvolvimento local da RDS, tanto por conglomerar os moradores nas redes de sociabilidade quanto pela centralização da rede política, cultural e econômica, portanto ambiental.

Na comunidade Nova Geração, localizada à margem esquerda do Rio Igapó-Açu, os centros se manifestam interna e externamente à comunidade, sendo uma comunidade policêntrica. Dessa forma, um dos centros da margem esquerda localiza-se na beira do Rio Igapó-Açu (Figura 10), sem construção física visivelmente estabelecida, como em São Sebastião do Igapó-Açu. Porém, o outro centro estabelece-se também no Chapéu de Palha, por seu caráter integrador. 


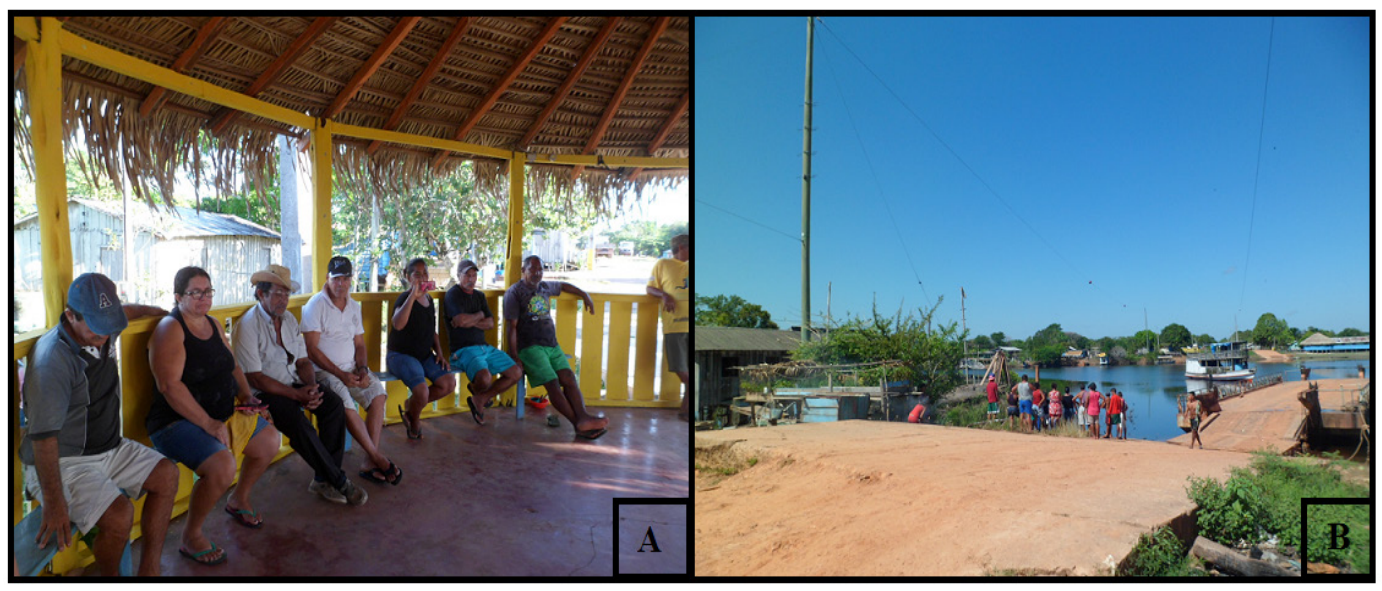

Figura 10 - Localização dos centros da Comunidade Nova Geração.

Esquerda: Chapéu de Palha; Direita: Centro sem construção física. Fonte: REZENDE, 2015.

O centro da Figura 10B não possui construção física visível, como na Figura 10A, entretanto, há uma customização do espaço para os encontros cotidianos da comunidade. Nos intervalos das atividades produtivas e nos finais de tarde, os moradores da Nova Geração se reúnem para conversas e troca de informações.

Dessa forma, pode-se observar que a RDS Igapó-Açu é uma unidade territorial policêntrica, pela existência de vários centros que compõem a centralidade dessa UC. Nesse sentido, a existência de vários centros em uma UC que apresenta conflitos entre duas comunidades, como é o caso da RDS Igapó-Açu, favorece o desmanche do nó górdio existente. Todavia, o policentrismo possui também suas limitações no que concerne ao ordenamento territorial. Kloosterman e Musterd (2001) afirmam que a aplicabilidade das políticas territoriais, com a vantagem do policentrismo, só seria possível por meio do reconhecimento identitário e da pertença dos grupos sociais envolvidos. A ausência do sentimento de pertença regionalista obsta qualquer aspecto positivo do sistema policêntrico.

Assim sendo, percebem-se os inúmeros desdobramentos do policentrismo na questão territorial e regional. Outro autor que analisa profundamente os desdobramentos do policentrismo é Pessoa (2011). Essa teórica acentua a importância do entendimento das duas dimensões formadoras do sistema policêntrico: a dimensão analítica, que objetiva a explicação do policentrismo; e a dimensão normativa, que objetiva formular estratégias políticas orientadoras para os centros existentes.

Apesar do ecletismo de teorias relacionadas ao surgimento e desenvolvimento do policentrismo, há semelhanças de pontos de vista. Os autores reconhecem a vantagem da pluralidade de centros em uma mesma região, no que concerne ao desenvolvimento local. Entretanto, o policentrismo potencializa-se a partir da coesão territorial no reconhecimento da importância da integração espacial entre os membros de uma comunidade.

Como foi descrito anteriormente, na RDS Igapó-Açu o sistema policêntrico confere benefícios significativos como a integração por meio dos interesses cônjuges entre a Comunidade São Sebastião do Igapó-Açu e a Comunidade Nova Geração. Porém, para propiciar o desenvolvimento da RDS, de forma geral, é necessária a intensificação da participação social mediada pelo pertencimento à UC.

Dessa forma, pode-se perceber que a governança ambiental da área de estudo perpassa inúmeras questões, sejam elas sociais, políticas, econômicas ou culturais. Para entendê-la em sua concretude foram elucidados alguns aspectos fundamentais que regem a rede de articulação política, como os elementos da governabilidade, do governo, as centralidades da rede política, e o policentrismo no ordenamento territorial. 
Pode-se inferir que a RDS Igapó-Açu possui inúmeras particularidades políticas, devido ao ecletismo de interesses que envolvem esta UC. O Conselho Gestor, com sua característica de centralidade, materializa a rede de articulação política das comunidades estudadas, sendo o instrumento primordial que constitui a governança ambiental. Essa miríade de governação envolve sistemas simbólicos e sociopolíticos que conformam o governo, interferem na governabilidade e estabelecem a governança. O resultado da interação sistêmica entre todos os fatores supracitados materializa a complexidade da organização social, que resulta no ordenamento territorial da RDS Igapó-Açu.

\section{CONSIDERAÇÕES FINAIS}

Compreender a governança ambiental da RDS Igapó-Açu, junto ao ecletismo de atores sociais que configuram a rede de articulação política, significa elucidar lacunas anteriormente construídas. Toda elucidação, como a própria palavra expressa, ilumina aspectos até então obscurecidos e invisibilizados. Dessa forma, trabalhar um conceito de governança ambiental em uma UC com centralidades de poder policêntricas, foi o desafio deste artigo.

A RDS Igapó-Açu foi compreendida e analisada pela lógica dos sistemas simbólicos e sociopolíticos, no âmbito da governabilidade e do governo, na constituição da governança ambiental. Entretanto, o processo perceptivo e reflexivo de construção necessitou da utilização de autores das variadas áreas do conhecimento, pelo fato do problema da pesquisa requerer uma inflexão transdisciplinar.

Entendido todo o processo de construção epistemológica, pode-se inferir que a centralidade da governança ambiental da RDS Igapó-Açu é o Conselho Gestor. O Conselho proporciona e materializa a governabilidade da UC, pela realização das reuniões bimestrais entre os atores sociais que atuam na RDS. Paralelamente, o governo aparece mediado por outros aspectos, não somente pelo viés político, diferentemente dos outros elementos que compõem a governança.

Os múltiplos centros dessa rede da governança, que configuram o policentrismo, integram as comunidades São Sebastião do Igapó-Açu e Nova Geração, na medida em que potencializa as atividades cônjuges entre as duas localidades e minimiza os aspectos negativos advindos da relação territorial conflitiva. A sustentabilidade da atual rede de articulação política da área de estudo depende da atuação do Demuc, órgão que centraliza os fluxos de poder.

Pode-se afirmar que a construção da governança ambiental da RDS Igapó-Açu inicia-se nos sistemas simbólicos, permeada por redes policêntricas e por campos de forças, que originam os sistemas sociopolíticos. A interação entre esses sistemas conforma a rede da governança ambiental, constituída pelos atores envolvidos e atuantes na UC. Dessa forma, o ordenamento territorial da RDS Igapó-Açu emerge da interação entre esses elementos, sendo reflexo da governança e de seus desdobramentos temporais.

O entendimento da governança a partir dos sistemas simbólicos e sociopolíticos, conformadores do governo e da governabilidade, é uma proposição teórica importante, que acrescenta na discussão da governança ambiental elementos importantes, como as formas de organização social e seus desdobramentos no modus operandi da rede de articulação política. Portanto, a partir das lacunas identificadas nos estudos referentes à governança, este trabalho evidenciou a necessidade de inserção das formas de organização social na compreensão da organização e constituição da governança ambiental.

\section{NOTAS}

\footnotetext{
${ }^{1}$ Maturana e Varela (1995) concebem autopoiese como sendo a capacidade de reprodução dos seres vivos que conferem as condições necessárias para a vida.

${ }^{2}$ Segundo Santos (1994), as metamorfoses do espaço são a expressão das transformações ocorridas entre o externo e o interno, e entre o novo e o velho, de modo que em um mesmo território ou em um mesmo lugar existem variáveis de idades diferentes, decorrentes da interação dialética entre os elementos supracitados.
} 
${ }^{3} \mathrm{O}$ conceito de significado utilizado neste artigo baseia-se no conceito de Roland Barthes (1991), que afirma que o significado é a representação psíquica, e também social, de uma "coisa", não sendo a "coisa" em sua essência, mas a construção de uma realidade.

${ }^{4}$ Os significantes são o conjunto de elementos que fundamentam a construção da significação à percepção (GREIMAS, 1973). Os signos representam, assim, a materialização da interação entre o significado e o significante, dialeticamente.

${ }^{5} \mathrm{O}$ conceito de topofilia foi cunhado pelo geógrafo Yu-Fu Tuan, em 1974. Para o autor, a topofilia é o elo afetivo estabelecido entre os indivíduos e o ambiente. É o espaço vivido que traduz as experiências concretas por meio da realidade construída simbolicamente.

${ }^{6}$ Segundo Geertz (2008), a cultura forma-se a partir das construções simbólicas, por meio de uma constelação de símbolos carregados por uma teia de significados.

${ }^{7}$ Segundo Baechler (1996), a sociabilidade é a capacidade humana de compartilhamento e socialização das normas sociais. Ocorre por meio de uma rede de solidariedade que se materializa por meio do processo de socialização.

\section{REFERÊNCIAS BIBLIOGRÁFICAS}

BAECHLER, J. Grupos e sociabilidade. In: Tratado de Sociologia. Rio de Janeiro: Editora Jorge Zahar, 1995.

BARTHES, R. Elementos de Semiologia. São Paulo: Cultrix, 1972.

BIERMANN, F. Global Environmental Governance: conceptualization and examples. In: Global Governance, Amsterdam, 2004.

BOURDIEU, P. O poder simbólico. Rio de Janeiro: Bertrand Brasil, 2005.

BRASIL. Lei n. 11.699, de 13 de junho de 2008. Dispõe sobre as Colônias, Federações e Confederação Nacional dos Pescadores. Brasília, 2008.

CASTELLS, M. A sociedade em rede - a era da informação: economia, sociedade e cultura. São Paulo: Editora Paz \& Terra, 2002.

DELMAS, M; YOUNG, O. Governance for the environment: new perspectives. Cambridge University Press, 2009.

DIAS, L. Redes: emergência e organização. In: Geografia conceitos e temas. GOMES, P. C. C. (Org.). Rio de Janeiro: Editora Bertrand Brasil, 1995.

DUARTE, L. M. G. A questão energética: sustentabilidade do desenvolvimento ou desenvolvimento da sustentabilidade? In: Esquina da Sustentabilidade: um laboratório da biocivilização. Brasília: Editora da Universidade de Brasília, 2014.

ELIAS, N. Teoria simbólica. Celta Editora: Oeiras, 1994.

ESTY, D. C.; IVANOVA, M. H. Globalization and Environmental Protection: a Global Governance Perspective, New Haven, 2003.

GEERTZ, C. A interpretação das culturas. Rio de Janeiro: LTC, 2008.

GOMES, R. de S. A dupla face do sindicalismo em Manaus. XI Congresso Luso Afro Brasileiro de Ciências Sociais, Salvador, 2011.

GREIMAS, A. J. Semântica estrutural. Editora Edusp. São Paulo: Cultrix, 1973.

HAESBAERT, R. Blocos internacionais de poder. São Paulo: Editora Contexto, 1994.

HAESBAERT, R.; GONÇALVES, C. W. P. A nova des-ordem mundial. São Paulo: Editora Unesp, 2005. 
KLOOSTERMAN, R; MUSTERD, S. Região urbana policêntrica: caminhos de uma investigação cotidiana. Revista Urban Studies, 2001.

LATOUR, B. Reassembling the social: an introduction ork-theory. EUA: Oxford University Press, 2005.

LEFEBVRE, H. A revolução urbana. Belo Horizonte: Editora da Universidade Federal de Minas Gerais, 1999. Espaço e política. Belo Horizonte: Editora da Universidade Federal de Minas Gerais, 2008.

LEMOS, M; AGRAWAL, A. Environmental Governance. Annual Review of Environment and Resources, 2006.

LOPES, I. dos S. et al. Políticas públicas e a busca pela garantia dos direitos dos pescadores artesanais: um estudo da Colônia dos Pescadores Z-17 em Parintins/AM. VI Jornada Internacional de Políticas Públicas, Maranhão, 2013.

MATURANA, H.; VARELA, F. A árvore do conhecimento: as bases biológicas do conhecimento humano. São Paulo: Editorial Psy II, 1995.

MO, J. Placing the G20 in the Emerging System of Global Governance. Hills Governance Center at Yonsei Working Paper, p. 2-13, 2010.

NAJAM, A.; PAPA, M.; TAIYAB, N. Global Environmental Governance: a Reform Agenda. International Institute for Sustainable Development, 2013.

NASCIMENTO, E. P. Trajetória da sustentabilidade: do ambiental ao social, do social ao econômico. Revista Estudos Avançados, v. 26, n. 74, São Paulo, 2012.

PESSOA, R. P. P. Em busca de uma definição de policentrismo urbano para as metrópoles brasileiras. Revista Paranaense de Desenvolvimento, 2011.

PINTO, J. A. R. Direito sindical e coletivo do trabalho. São Paulo, 2002.

RIBEIRO, W. da C. A ordem ambiental internacional. São Paulo: Editora Contexto, 2005.

SANTOS, M. Metamorfoses do espaço habitado. 3. ed. São Paulo: Editora Hucitec, 1994.

SISTEMA NACIONAL DE UNIDADES DE CONSERVAÇÃO. Decreto n. 4.340, de 22 de agosto de 2002. Regulamenta artigos da Lei n. 9.985, de 18 de julho de 2000, que dispõe sobre o Sistema Nacional de Unidades de Conservação da Natureza - Snuc, e dá outras providências.

TUAN, Y. F. Topofilia: um estudo da percepção, atitudes e valores do meio ambiente. São Paulo: DIFEL, 1974.

VEIGA, J. E. da. O mundo em transe: do aquecimento global ao ecodesenvolvimento. Editora Armazém do Ipê, 2009. 